\title{
Führer durch das mittelalterliche Jenseits - eine Übersicht
}

\author{
Jan Slíva
}

(Masaryk University, Brno)

\section{Guide of Medieval Otherworld - an Overview}

\begin{abstract}
A guide of an underworld tour is one of the significant features in medieval visionary literature as well as in ancient catabases and Jewish-Christian apocalyptic. It represents an archetype and universal motif of many otherworld journeys through the centuries and cultures. This paper based on a huge collection of sources investigates this topos in medieval visionary accounts composed between the $6^{\text {th }}$ and $13^{\text {th }}$ century. Here the most frequent appearing guide figure is an angel, especially an archangel or a guardian angel. In many other visions a saint holds the role of an instructor and protector. It is almost always possible to find a closer relation between the saint and the visionary - a kind of patronage (personal or local patron). The third usual guide type represents a human connected to the visionary with a spiritual bond (confrère, superior) or a blood relationship (family member). This paper introduces a short characteristic of these three basic otherworld guides and offers a list of all visionary records from the mentioned period including this figure.
\end{abstract}

\section{Keywords}

otherworld guide; otherworld vision; visionary literature 
Visionen gehörten zu einem verbreiteten Phänomen der christlichen Gesellschaft des Mittelalters. Sie bezeichnen ein außerordentliches psychosomatisches Erlebnis, bei dem ein Mensch „aus seiner natürlichen Umwelt durch den Eingriff einer äußeren Gewalt in einen anderen Raum versetzt wird."1

Schon die ältesten frühmittelalterlichen Visionen, meistens im Rahmen der historiound hagiographischen Literatur überliefert, schildern die Versetzung eines Menschen ins Jenseits. Das aus diesen kurzen Berichten im Laufe der Jahrhunderte entwickelte eigenständige Genre erreichte seinen Höhepunkt im 12. Jh., in welchem die meisten, umfangreichsten und literarisch anspruchsvollsten Jenseitsvisionen aufgezeichnet worden sind. ${ }^{2}$ In den folgenden Jahrhunderten überwog dann ein anderer Visionstypus mystische Offenbarungen, deren Akteurinnen im Allgemeinen Mystikerinnen und Charismatikerinnen waren und in deren Mittelpunkt der intime Kontakt mit Gott, vor allem in Form der Erscheinung der Gestalt Jesu Christi, stand. ${ }^{3}$

Die Schilderung einer Jenseitswanderung ist selbstverständlich kein Novum der mittelalterlichen Literatur. Ein Descensus ad inferos ist schon aus antiken Mythen und Epen gut bekannt. Auch in den Apokryphen und der jüdisch-christlichen Apokalyptik findet sich dieses Thema. Eines der Grundelemente, welches die antiken, jüdischen sowie christlichen Jenseitsgeschichten von der Odyssee bis zu Dantes Göttlicher Komödie durchdringt, ist die Figur eines Jenseitsführers. Dieser Archetyp steht ohne Zweifel im Zusammenhang mit der allgemein menschlichen Vorstellung von der Schwierigkeit, ins Totenreich zu gelangen. ${ }^{4}$

Dieser Beitrag versucht, anhand eines umfangreichen Quellenmaterials lateinischer, vom Anfang des 6. bis zum Anfang des 13. Jh. aufgezeichneter Jenseitsvisionen, die bisher herausgegeben worden sind, den Topos eines Jenseitsführers bzw. -begleiters vorzustellen. ${ }^{5}$ Gemäß der eingangs zitierten Definition konnten nahezu 100 Visionen als Jenseitsvisionen, d. h. Visionen, in denen die Versetzung eines Menschen ins Jenseits

1 Dinzelbacher (1991: p. 17).

2 Dinzelbacher (1991: p. 30).

3 Zu den Unterschieden zwischen diesen zwei Visionstypen vgl. Dinzelbacher (1981: pp. 229ff).

4 Ein Seelengeleiter ist in vielen Religionen bekannt. In der antiken Mythologie erledigte diese Aufgabe der Gott Hermes (Merkur), im alten Ägypten der Gott Anubis. In der jüdisch-christlichen Tradition übernahmen Engel die Rolle des Seelenführers; siehe Krauss (2001: pp. 133f, s. v. psychopompos).

5 Grundlage für die Arbeit war die Visionsliste, herausgegeben in der Reihe Typologie des sources du Moyen Âge occidental (Revelationes, Band 57) - Dinzelbacher (1991: pp. 89-108), die trotz kleiner Fehler ein sehr gutes Ausgangsmaterial zur Verfügung stellt. Dieses Verzeichnis verglich ich mit dem Index Visionum medii aevi latini repertorium - Fros (1988: pp. 481-498) und dem Handbuch Medieval Visions of Heaven and Hell: A Sourcebook - Gardiner (1993). Das daraus zusammengesetzte Korpus wurde noch um weitere neu herausgegebene Visionsberichte ergänzt. Die chronologisch letzte untersuchte Vision ist die Visio Thurkilli aus dem Jahr 1206. Dieser Aufsatz erhebt nicht den Anspruch, vollständig alle Visionsaufzeichnungen für den bestimmten Zeitraum zu erfassen. Viele der Visionen sind noch ungedruckt oder warten auf ihre Entdeckung. Vgl. Gebauer (2013). Die zitierte Dinzelbachers Studie (1991) sowie das Gardiners Sourcebook (1993) enthalten auch zahlreiche bibliographische Angaben zum Thema Visionen, ebenso die von Dinzelbacher (1994) erstellte Forschungsübersicht Nova visionaria et eschatologica. Von später herausgegebenen Monographien müssen zum Forschungsthema mindestens noch diese 3 genannt werden: Carozzi (Le Voyage de l'âme dans l'au-delà d'après la littérature latine, 1994), Weitbrecht (Aus der Welt, 2011), Benz (Gesicht und Schrift, 2013). 
beschrieben wird, identifiziert werden. Davon sind 69 Visionen ausgewählt worden, in denen die Figur eines Jenseitsführers vorkommt. ${ }^{6}$ In diesem Aufsatz sollen gerade diese Visionen im Fokus näherer Betrachtung stehen. ${ }^{7}$

Alle wesentlichen, bis zum 13. Jh. aufgezeichneten Werke der Visionsliteratur erwähnen einen Jenseitsbegleiter. Die Forscher, die sich mit dem Phänomen der Vision näher auseinandergesetzt haben, weisen wiederholt auf dessen Bedeutung hin; eine komplexe zusammenfassende Studie zu dieser Figur gibt es dennoch nicht. ${ }^{8}$ Der folgende Aufsatz hat nicht die Ambition, diese Forschungslücke zu füllen. Er verfolgt vielmehr das Ziel, verschiedene Typen des Jenseitsführers und seine Wesensmerkmale, wie sie in den Visionsberichten beschrieben sind, vorzustellen. In diesem Zusammenhang sollen auch einige Erlebnisse der Visionäre, die in ihrer Jenseitsvision einem Begleiter begegnen, wiedergegeben werden. Ein Quellenverzeichnis zu den untersuchten Visionen wird dem Aufsatz beigefügt und möge als Grundlage für weitere Forschungen zum Thema dienen.

Die Figur des Jenseitsführers bildet einen wesentlichen Bestandteil eines Schemas, das vielen Visionsberichten zugrunde liegt: ${ }^{9}$ ein Visionär wird zuerst von einem Führer ins Jenseits gebracht, auf seiner Reise weiter begleitet, beschützt und belehrt und am Ende in seinen Körper zurückgebracht.

Es ist keine große Überraschung, dass der am häufigsten vorkommende Begleiter eines Visionärs auf seinem Jenseitsweg ein Engel ist. Diese Tatsache entspricht der Funktion, in der die Engel in der Bibel auftreten ( $L c$ 16,22). Eine ihrer Aufgaben ist, einen Menschen (Gn 24,7.40; Ps 91,11) sowie das ganze Volk (Ex 23,20.23) zu beschützen und zu begleiten. ${ }^{10}$ Auch die jüdisch-christliche Apokalyptik sieht in der Figur des Jenseitsführers einen Engel. ${ }^{11}$ Ein Engel oder eine Engelgruppe begleitet die Seher insgesamt in 29 Visionsberichten und natürlich erscheinen diese mächtigen Helfer auch in vielen anderen Visionen als wichtige Personen des Himmelsreiches. ${ }^{12}$

6 Es gibt noch 8 sehr kurze Visionsberichte, die die Figur eines Jenseitsführers nicht explizit erwähnen; aus den verwendeten lexikalischen Mitteln, besonders den Passivformen des Verbes ducere, ist sie dennoch vorauszusetzen. Es handelt sich hierbei um die Visio Sunniulfi, Visio Stephani, Visio Wanningi, Visio Wernheri, Visio cuiusdam viri religiosi, Visio prioris de Cogeshala, Visio unius fratris Claravallensis, Visio Wolferadi.

7 Visionsserien eines Sehers sind als eine Angabe gezählt. Falls mehrere Versionen von derselben Vision überliefert sind, wurde nur die älteste überlieferte Aufzeichnung beachtet.

8 Grundkenntnisse hierzu liefert Dinzelbacher (1981: pp. 146-169). Für Zaleski (1993: p. 82) repräsentiert der Seelenführer einen Archetypus und ein universelles Prinzip. Und Díaz y Díaz (1985: pp. 25-30) spricht in diesem Zusammenhang von einem obligatorischen Motiv der Visionsliteratur.

$9 \quad$ Vgl. Schmidt (1997: p. 153).

10 Die Vulgata bezeichnet die menschlichen Boten als nuntii und himmlische Boten als angeli; siehe THAT I (Jenni \& Westermann 1978: p. 908, s. v. mal'āk Bote).

11 In der Visio beati Esdrae, dem zwischen dem 4. und 6. Jh. entstandenen und von dem 4. Buch Esra ausgehenden Text, wird Esra von sieben angeli tartarei durch die Unterwelt geleitet. In den Himmel wird er danach von den Erzengeln Michael und Gabriel aufgenommen. In der einflussreichen Paulusapokalypse wird der Apostel auch durch einen Engel geführt. Aus diesem sehr beliebten Text entwickelte sich im christlichen Abendland die Visio Pauli, die in mehr als 100 Handschriften aus dem 10. bis 16. Jh. überliefert ist; siehe Dus (2007: pp. 253-313), Jiroušková (2006).

12 Die Engel (angelus corusci habitus; boni spiritus) als Retter vor dem Bösen kommen auch in den Visionen vor, die Gregor der Große in seinen Dialogi (IV,36) zusammentrug. Diese Schrift ist wohl nach der Bibel die am häufigsten zitierte Quelle in der ganzen Visionsliteratur. 
Beliebt waren vor allem die Erzengel. Die Visio Baronti, die erste als selbstständiger Text erhaltene Jenseitsvision, nennt den Erzengel Raphael (sanctus Rafahel) als Begleiter, ebenso wie die Visio Gunthelmi (sanctus Raphael archangelus), in der Raphael den Visionär ins Paradies geleitet. Der Erzengel Michael erscheint in beiden Visionen der Mönche von St. Vaast (dominus sanctus Michael; pacis et lucis Michael angelus), in der Vision des harmlosen Orm (vir venerabilis, Michael archangelus) und der des Bauern Thurkill (sanctus Michael archangelus). ${ }^{13}$ Die Visio Alberici führt namentlich die Engel Eloi und Emanuel (Hemmanuel; Heloy) auf und der Zisterziensernovize Zacharias wird von dem Engel Barachias beschützt. ${ }^{14}$ In den übrigen Texten geht es um namenlose Engel (angeli; caelicolae).

Das Hauptattribut der Engelführer ist Licht, das sie umgibt oder direkt von den Engelwesen ausstrahlt. Die Mystikerin Christina die Wunderbare $(\uparrow 1224)$ nennt die Engel in ihrer Vision Lichtdiener. ${ }^{15}$ Der Erzengel Raphael in der Visio Baronti strahlt vor Lichterglanz (in splendore claritatis fulgidus) und in der Visio Rotcharii funkelt die Engelgestalt vor übermäßigem Glanz (nimio splendore coruscus). ${ }^{16}$ Laut dem Ritter Tnugdal ist das von einem Engel ausgehende Licht manchmal so stark, dass es an einen Stern erinnert. ${ }^{17}$ Infolge des blendenden Lichtes ist der Seher nicht in der Lage, seinen Begleiter direkt anzusehen oder irgendwelche Details dessen Körpers zu betrachten. ${ }^{18}$ Die physische Beschreibung von Engeln ist daher meistens nur auf ihr Antlitz begrenzt. ${ }^{19}$ Von ihnen geht Schönheit und Ehrwürdigkeit aus. Der Reichenauer Mönch Wetti erwähnt, dass sein Engelsbegleiter in unglaublicher Herrlichkeit glänzte (angelus incredibili splendens pulchritudine.${ }^{20}$ Die Begleiter des Holsteiner Bauern Gottschalk wurden als zwei Engel schön von Angesicht, in schneeweißem Gewand und gemessener Haltung geschildert (duo angeli vultu venusto, habitu niveo, gestu modesto $)^{21}$ und der Mönch Maximus vermag,

13 In der Vision des Bauern Thurkill tritt noch der Engel Uriel als der Hüter des reinigenden Feuers auf; Visio Thurkilli (p. 33): ... Uriel angelus, erat custos ignis purgatorii suprascripti, ... Derselbe Engel erscheint auch in der Esra-Apokalypse oder der altirischen Vision des Adamnán. Die Namen Michael und Gabriel finden sich im alttestamentlichen Buch Daniel (10,13.21 und 8,16; 9,21) erwähnt. Von dem Erzengel Raphael wird auf seiner Reise nach Medien Tobias begleitet ( $T b 5,4 \mathrm{ff}$ ). Alle vier Erzengel zusammen führt das pseudepigraphische 1 . Henochbuch $(9,1)$ an.

14 Die Bibel erwähnt Barachias als Vater des Hohepriesters Zacharias (Mt 23,35). Auch in der Vision nennt der Engel den Seher seinen Sohn (Visio Zachariae, p. 280: Ergo meus es tu filius.). Barachias ist auch eine der möglichen Varianten des Namens Barakiel und einer der Erzengel in der Tradition der orthodoxen Kirche; siehe Davidson (1967: p. 69, s. v. Barakiel).

15 Visio Christinae Mirabilis, (col. 561F): ... susceperunt meam animam ministri lucis, angeli Dei...

16 Visio Baronti (p. 379); Visio Rotcharii (p. 73).

17 Visio Tnugdali (p. *10): Misit namque angelum suum in occursum eius, quem respiciens a longe venientem quasi stellam lucidissimam.

18 Visio Wenlocensis monachi (p. 252): ... tam magnae claritatis et splendoris angeli, ut nullatenus pro nimio splendore in eos aspicere potuisset; Visio Fursei (p. 679): ... mirifico splendentes fulgore facies, claritatem eximiae lucis ex ipsis angelicis intuebatur conspectibus, nec aliquid corporeum nisi luminis claritatem potuit uidere.

19 Visio Cisterciensis fratris (p. 85): ... qui faciem quidem humanam luce splendidiorem preferebant, sed tamen pedes aut manus ceteraque menbra corporea, prout videbatur, penitus non habebant.

20 Visio Wettini (p. 269).

21 Visio Godeschalci (p. 54). 
die Pracht seiner Betreuer keinesfalls darzulegen. ${ }^{22}$ Der Junge Orm beschreibt wiederum seinen Engelsbegleiter ausführlich. Außer dem strahlenden Aussehen, dem wunderschönen Gesicht, dem schneeweißen Haar und dem noch weißeren Gewand mit rotem Mantel ist vor allem der fröhliche und beruhigende Blick des Engels hervorzuheben, der den Visionär mit Freude erfüllt..$^{23}$

Der Mönch aus dem Kloster Vaucelles wurde von einer riesigen weißen Taube ins Jenseits getragen, die sich gleich als des Visionärs Schutzengel vorstellte. ${ }^{24}$ Ähnlich wurde die Seele des Jünglings Baldarius von drei herrlichen Tauben in die himmlischen Sphären zu Gott entführt. ${ }^{25}$ Auch Alberich beschreibt einen weißen, einer Taube ähnlichen, Vogel, der seinen Schnabel in Alberichs Mund steckte und etwas aus ihm herauszog. Dann packte der Vogel den Seher mit dem Schnabel am Haupthaar und hob ihn empor. ${ }^{26}$ Und die hl. Sadalberg wurde von einem schneeweiß strahlenden in einem herrlichen Tabernakel aufbewahrten Vogel in die andere Welt gebracht. ${ }^{27}$

In wenigen Visionen tritt der Jenseitsführer als unscheinbare, nicht sofort erkennbare Person auf. Der Visionär führt nirgendwo explizit an, dass es sich um einen Engel handele, trotzdem ist es nach seiner Beschreibung anzunehmen. Der Hausvater Drycthelm bezeugt, dass er von einer hellen Gestalt in weißer Kleidung begleitet wurde (lucidus aspectu et clarus erat indumento), ${ }^{28}$ sodass sie ihm ein in der Finsternis glänzender Stern zu sein schien, als er sie erneut kommen sah. ${ }^{29}$ In der Vision Karls des III. ist der Begleiter des Kaisers ein ductor candidissimus, ${ }^{30}$ in der Visio Guillelmi wiederum ein vir splendidus, ${ }^{31}$ in der dichterischen Visio Aethelwulfi beschützt den Poeten ein weißer Begleiter in prächtiger Kleidung und mit hübscher Miene strahlend. ${ }^{32}$ Der Mönch Reiner von Lüttich wurde von

22 Visio Maximi (col. 431C): ... angelus lucis, cujus pulchritudinis comparationem non valeo enarrare.

23 Visio simplicis Orm (p. 78): ... fulgido preclarus habitu [et] pulcherrimo vultu splendidus, hylaris quoque multum et gaudens aspec[tu], quem intueri multum delectabar. Capilli eius candidi erant sicut nix, rubicund[o] vestimento erat indutus, sub quo aliud habebat nive candidius indumentum.

24 Visio monachi in Vacellis claustro (p. 160): ... ecce columba candoris mirifici, set multum maioris corpulentie quam columba! ... Ipse autem voce gratissima respondit meis questionibus in hunc modum: „Ego sum angelus ad tui custodiam deputatus, ... "Von ihrem Schutzengel werden durch das Jenseits auch Wetti und Tnugdal begleitet.

25 Visio Baldarii (col. 435D).

26 Visio Alberici (p. 168): ... avis candida, columbe similis, adveniens rostrumque suum in os meum iniciens, nescio quid exinde abstrahi sentiebam, ac deinde per comam capitis suo me ore apprehendens, ferre cepit, ...

27 Visio Sadalbergae (p. 64): ... vidit... tabernaculum e polo mirae claritatis et splendoris descendere...; in quo recepta avis miri candoris ac splendore nimio fulgens, ...

28 Visio Drycthelmi (p. 68).

29 Visio Drycthelmi (p. 72): ... quasi fulgor stellae meantis inter tenebras, ... Genau denselben Eindruck über den ankommenden Engel bekommt auch der Ritter Tnugdal; siehe Anm. 17. Eine neue Version der Vision Drycthelms schrieb Helinand von Froidmont († nach 1229) in seiner Chronik nieder. Helinand führt schon klar einen Engel als Führer an. Helinandi Frigidi montis monachi Chronicon, (col. 1059B): Quidam pulcher angelus in veste nitidissima duxit me...

30 Visio Karoli Crassi (p. 161).

31 Visio Guillelmi (col. 1036B).

32 Visio Aethelwulfi (p. 601, v. 4-7): Candidus en subito videbatur ductor adesse, / Hunc ego praepavidus nitidis iam vestibus album / Vultibus ac pulchris radiantem... 
einem Jüngling engelhafter Anmut geführt, ${ }^{33}$ der hl. Dunstan, späterer Erzbischof von Canterbury $(\uparrow 988)$, spricht dagegen von einem in schneeweißem Glanz erstrahlenden Greis. $^{34}$

Das Gegenteil zu den Engelwesen stellen Dämonen, Teufel und böse Geister in verschiedener Gestalt dar. Der Visionär wird von ihnen durch verschiedene Höllenkreise geschleppt und muss viele Qualen und Foltern am eigenen Leib erfahren. Er selbst ist gegen den Zorn der Dämonen machtlos. Errettet aus deren grauenvollen und böswilligen Spiel wird er dann nur durch seinen tatsächlichen Jenseitsführer, mit dem er sich auf eine Wanderung durch das Paradies begibt. Solch eine Vision ereilte die Mönche Barontus, Bonellus oder den Mönch von St. Vaast. Das bekannteste Beispiel dafür, dass ein Visionär, der sich in der Gefangenschaft böser Mächte befindet, eine schauderhafte und schmerzvolle Jenseitswanderung erlebt, ist zweifellos die Vision des sündigen Ritters Owein. ${ }^{35}$

Zur direkten Konfrontation mit Satan, der sich in den Tiefen der Hölle verbirgt, oder mit Gott, der im Glanze des Himmels thront, kommt es nur selten. Auch die Person Jesu Christi erscheint in den untersuchten Jenseitsvisionen nur spärlich. Als Begleiter wird er in den unten aufgeführten Visionsberichten nur dreimal erwähnt. ${ }^{36}$ Der Junge Agustus gelangt in seinem am Anfang des 7. Jh. niedergeschriebenen Visionserlebnis zu einem himmlischen Gastmahl, unter deren Gästen Christus als Gastgeber weilt. ${ }^{37}$ Jesus beruhigt den vor Ehrfurcht erstarrten Jüngling, sichert ihm seine beständige Hilfe zu, nimmt ihn bei der Hand und führt ihn durch die Himmelslandschaft. ${ }^{38}$ In der Vision des Mönches Ansellus aus dem 11. Jh. geleitet Christus den Seher auch durch die Hölle und den Ort der Läuterung. ${ }^{39}$ Auf dem Rückweg muss einer der Dämonen im Auftrag Jesu Ansellus zum Diesseits zurückbringen. ${ }^{40}$ St. Godrich von Finchale $(† 1170)$ wird von Christus samt dem Apostel Petrus und Johannes dem Täufer durch das Paradies begleitet. ${ }^{41}$ Auch Erwähnungen der Jungfrau Maria sind in der Visionsliteratur bis zum 13. Jh.

33 Visio Raineri (col. 1061D): ... angelicae venustatis quidam juvenis...

34 Visio Dunstani (col. 1427C): ... viditque mentis excessu quemdam senem niveo candore vestitum, ...

35 Der Ritter Owein ist der erste bekannte Besucher des Purgatoriums des hl. Patrick. Auf seiner Reise ins Jenseits wird Owein durchaus nach Belieben der Dämonen gequält: militem ... proiecerunt; torrerent; contraxerunt usw. Vgl. die lexikalische Analyse der Vision von Le Goff (1998: pp. 119ff).

36 In der Petrusapokalypse, deren ursprüngliche Version schon in der 1. Hälfte des 2. Jh. entstanden ist, zeigt Christus dem Apostel das Bild des Jüngsten Gerichts, Qualen der Sünder sowie die Himmelsfreuden der Gerechten auf seiner rechten Handfläche; siehe Dus (2007: pp. 316-348).

37 Visio Agusti (p. 142): In medio autem eorum veniebat vir splendidissimus nimiumque pulcherrimus, forma decorus, aspectu gloriosus, statura procerior cunctis, lucidior sole, candidior niue... sedit pulcrior ille uir in eminentiori loco, ceteri uero procidentes adorantesque eum residerunt in sedibus suis.

38 Visio Agusti (p. 144): „Noli timere. Scito quia protector tuus ero. Numquam tibi aliquid deerit. Ego te semper pascam, ego te semper vestiam, ego te omni tempore protegam et numquam derelinquam. “... et adpreendens manum meam eduxit me in ortum amoenissimum, ...

39 Die Visio Anselli beginnt am Palmsonntag während der Lesung der Passion, als Christus plötzlich vom Kreuz hinabsteigt und den Mönch auffordert, ihm zu folgen.

40 Visio Anselli (p. 193): „Serve“, inquit, „male, minister inique, quod iubeo cito perfice. Hunc fratrem incolumem ad pristinam patriam revoca et non eum dimittas donec loco suo restituas. Vide ne ab aliquo ledatur, sed cuncti inimici euis potestate regia terreantur. “

41 Visio Godrici de Finchale (p. 286): ... respondit eorum qualitatem, formam, atque figuram fore inexplicabilem, ac 
unüblich. ${ }^{42}$ Als Jenseitsführerin ist sie vermutlich nur in einer einzigen wahrscheinlich im 12. Jh. aufgezeichneten Vision zu finden. ${ }^{43}$ In diesem Visionsbericht rettet die Mutter des Erlösers einen Zisterzienser-Novizen vor dem Angriff eines riesigen Drachen, indem sie ihn mit ihren Armen umfängt und ihn in den Himmelspalast trägt. ${ }^{44}$

Andere zu erwartende Personen, denen die Visionäre auf ihrer Jenseitswanderung begegnen, mit denen sie Kontakt aufnehmen und sich von ihnen führen lassen, sind selbstverständlich die Heiligen. In erster Linie handelt es sich um die Apostel und Johannes den Täufer. Am häufigsten findet sich der hl. Petrus erwähnt, der als Besitzer der Schlüssel zum Himmelreich galt. ${ }^{45}$ In der Rolle eines Begleiters (nicht in allen Fällen als einziger) ist der Apostel zu finden in der Visio Votifragi, der Visio sancti Anskarii, der Visio Godrici de Finchale und der Visio Alberici, in der er sehr detailliert beschrieben wird. ${ }^{46}$ In der Visio Baronti übernimmt Petrus gegenüber dem Seher sowohl die Funktion eines Verteidigers als auch die eines Richters.

Zweimal erscheint auch der Apostel Bartholomäus als Begleiter. Der hl. Guthlac († 715), ein Mönch und späterer Einsiedler auf der Insel Crowland im nordwestlichen England, wird durch den Apostel von der Macht unreiner Geister befreit. ${ }^{47}$ Derselbe kommt auch Rahere († etwa 1145), einem Höfling des englischen Königs Heinrich des I., in seiner Vision zu Hilfe, die er während seiner Rückkehr von einer Pilgerfahrt nach Rom erlebte. Bartholomäus enthüllt seinem Schützling die Geheimnisse des Himmelsreiches und weist ihn an, eine Kirche zu seinen Ehren an einem konkreten Ort zu stiften. ${ }^{48}$

modum linguis hominum inedicibilem... Medius eorum erat magnus Jesus Nazaraenus, a dexteris Ejus coeli clavicularius Petrus, a sinistris vero ipsorum Johannes Baptista, ...

42 Eine wesentliche Rolle spielt die Jungfrau Maria jedoch in den Visionen der hl. Elisabeth von Schönau und der sel. Alpais von Cudot. Mit Maria spricht in seiner Vision der Mönch Gunthelm (Visio Gunthelmi, p. 107). In der Visio Thurkilli wird eine Jenseitskirche als die Basilika der hl. Maria und Versammlung der Seelen beschrieben (Visio Thurkilli, p. 11: basilica sancte Marie atque animarum congregatio).

43 Der Text ist in einer unvollständigen Handschrift aus dem Anfang des 15. Jh., die ursprünglich etwa 500 Visios- und Mirakelberichte enthielt, überliefert. Eine große Anzahl dieser Berichte nimmt Bezug auf die Person der Jungfrau Maria; siehe Constable (1956: p. 95).

44 Visio Cisterciensis novicii (p. 97): Mox affuit predicta misericordie mater Virgo Maria, et accipiens nouicium in ulnis suis ultra draconem portauit illum ad locum deliciosum ualde, ... Die Zisterzienser gehörten zu den groBen Verehrern Marias. Bis ins Jenseits drang auch ihr Konkurrenzkampf mit den Cluniazensern vor, der auch in dieser Vision deutlich wird. Während das Paradiestor der Zisterzienser prachtvoll geschmückt ist, verfällt das Tor der Mönche von Cluny (Visio Cisterciensis novicii, p. 98).

45 Mt 16,19.

46 Visio Alberici (p. 206): Ipsius autem beati Petri statura, quantum ego cognovi, nec longa multum nec brevis, set media et iusta erat, corpore compressus, vultu grossior, canis habens aspersum caput. Indutus erat tunica candidissima, quam circa pectus et collum torques aurea decorabat. Auream in capite gestabat coronam, claves quoque magnas manibus tenebat, in quibus omnium pretiosorum gemme inserte videbantur.

47 Die Vision ist Bestandteil der in der ersten Hälfte des 8. Jh. aufgezeichneten Vita sancti Guthlaci. Der Apostel Bartholomäus spielt im Leben des hl. Guthlac eine wichtige Rolle. Am Tag des hl. Bartholomäus kommt Guthlac zu dem Entschluss, sein Mutterkloster zu verlassen und Eremit zu werden (Vita sancti Guthlaci, p. 88).

48 Das bis heute funktionierende Krankenhaus und die Kirche des hl. Bartholomäus aus dem Jahr 1123 befindet sich in der City of London. Die Vision ist in dem Liber fundationis dieser Klosterkirche aufgezeichnet. Es handelt sich um eine typische Gründungsvision; siehe Dinzelbacher (1989: p. 82). 
Die Welt des Jenseits, mit den Augen eines Visionärs erblickt und durch einen Schreiber zu Pergament gebracht, kann als ein Spiegel der Sichtweisen und Strukturen der damaligen Gesellschaft betrachtet werden. ${ }^{49}$ Dies zeigt auch die Auswahl der Personen, die der Visionär im Jenseits sieht oder denen er begegnet. Die Erwähnung konkreter Heiliger in den Visionsberichten gibt nicht selten die Kirchenstruktur eines Ortes, an dem der Visionär lebte, wieder. Die Seher neigten in ihren Visionen dazu, Personen zu begegnen, die sie aus ihrem eigenen sozialen Umfeld gut kannten, denen sie sich verbunden fühlten und die sie besonders verehrten. Als Begleiter standen ihnen die Namenspatrone der Klöster und Kirchen zur Seite. Für die Geistlichen waren dies besonders die Schutzpatrone ihres Stiftes, Klosters oder die Gründer des Ordens, dem sie angehörten, für die Laien konnten dies ihre persönlichen Beschützer oder die Patrone der Kirche sein, in deren Pfarrei sie lebten.

Die Entstehung der Visionsliteratur war sehr eng an die Klöster gebunden. Hier wurden die Visionsberichte gesammelt und redigiert, abgesehen davon, dass die Mehrheit der Visionäre ohnehin Mönche waren. In den Visionsaufzeichnungen fehlt demnach auch nicht die Person des hl. Benedikt von Nursia. ${ }^{50}$ Als Begleiter ist Benedikt aber nur dem Mönche Gunthelm behilflich, um ihn durch die Jenseitslandschaft zur Jungfrau Maria zu begleiten. Die Zisterzienser, die größten Sammler von Visionen und Mirakeln, verknüpften viele der Wundererzählungen mit dem hl. Bernard von Clairvaux. Dieser Heilige erscheint in vielen Geschichten der Sammlung Liber miraculorum des Herbert von Clairvaux ( $\uparrow 1198)$. Eine Erzählung beschreibt die Vision eines Zisterzienserabtes, in der Bernard seinen Ordensbruder zu Jesus Christus geleitet. ${ }^{51}$

Edmund, Mönch von Eynsham, wird auf seiner Jenseitsreise vom hl. Nikolaus, dem Schutzpatron des Pfarrbezirkes, in dem Edmund aufwuchs, begleitet. ${ }^{52}$ Bruder Earnan wird wiederum durch den hl. Cuthbert und Oswald beschützt, deren Reliquien Earnans Mutterkloster in Durham aufbewahrte. ${ }^{53}$ Auch Johannes von Lüttich erscheinen in seiner Vision der Patron seines Mutterklosters, der hl. Laurentius, und der hl. Mauritius, der Patron einer jenem Kloster nahegelegenen Kapelle, die ihn beide begleiten. ${ }^{54}$ In der Vision des Mönches Isaak, die Otloh von St. Emmeram seiner Sammlung Liber visionum beigefügt hat, ${ }^{55}$ ist Isaaks Begleiter in die andere Welt der hl. Gunther, ${ }^{56}$ Gründer des Klosters Rinch-

49 Dinzelbacher (1979: pp. 16-34).

50 In der Vision des anderen Mönches von Pulsano spricht der hl. Benedikt, als Pater omnium monachorum bezeichnet, zugunsten des angeklagten Visionärs vor dem Jenseitsgericht (Visio alterius Pulsanensis monachi, col. 54E). Alberich wird während seiner Vision belehrt, dass der. hl. Benedikt zur Schar der Bekenner gehört. Benedikt genießt jedoch größeren Ruhm als die anderen Heiligen (Visio Alberici, p. 188).

51 Visio cuiusdam abbatis (p. 102). Diese kurze Vision bringt jedoch keine Jenseitsbeschreibung.

52 Visio Edmundi monachi de Eynsham (p. 270, Anm. 1).

53 Die Vision ist in einer Klosterchronik aus dem 12. Jh. aufgezeichnet. Zum hl. Cuthbert und Oswald siehe LexMa, s. v. Oswald und Cuthbert.

54 Visio Johannis Leodiensis (col. 184D).

55 Liber Visionum, Visio 14.

56 Gunter oder Günther (im Tschechischen Vintír genannt) war Mönch im bayerischen Kloster Niederalteich, später auch Einsiedler. Vgl. Život Vintíre poustevnika (pp. 337-346). Siehe auch LexMa, s. v. Gunther, Eremit. In der Vision erscheinen auch andere bedeutende Personen aus der tschechischen Geschichte: die Prager Bischofe Vojtěch (Adalbert) und höchstwahrscheinlich auch Šebír (Severus). 
nach, dem der Seher angehörte. Von zwei Gründern des Stiftes Condat, dem hl. Romanus und Lupicinus, wird der Junge Eugendus, der später in dieses Kloster eintritt, dort Abt wird und schließlich in den Fußstapfen seiner Amtsvorgänger Heiligkeit erlangt, begleitet. ${ }^{57}$ Der hl. Jakob der Ältere führt Heinrich von Ahorn, da der Visionär diesem früher versprochen hatte, eine Pilgerfahrt nach Santiago de Compostela zu unternehmen. ${ }^{58}$

Die Tendenz der mittelalterlichen Visionsliteratur, persönliche und lokale Patrone und Heilige zu bevorzugen und in ihnen auch die Figur des Jenseitsführers zu sehen, illustriert sehr deutlich die Visio Thurkilli. Thurkill, ein einfacher Bauer aus Essex, dessen Erlebnis im Jahr 1206 erfolgte, sucht im Jenseits nach seinen Eltern und sieht seine Freunde, Leute aus dem Pfarrbezirk und seinen früheren Herrn wieder. In diesem Visionsbericht tauchen eine Anzahl berühmter Heiliger auf: die Apostel Petrus und Paulus, die Heiligen Nikolaus, Katharina oder Margareta. Sie übernehmen in der anderen Welt unterschiedliche Aufgaben. Thurkill stehen zudem mehrere Führer zur Seite. Neben dem Erzengel Michael begleiten und schützen den Visionär der hl. Julianus Hospitator und der hl. Domninus von Fidenza. Beide können als Schutzpatrone Thurkills betrachtet werden. ${ }^{59}$ Der Visionär wird zuerst vor den hl. Jakob den Älteren gebracht, dem die Kirche in der nicht weit entfernten Ortschaft Dengie geweiht war und der Thurkill als peregrinus suus ${ }^{60}$ anspricht. ${ }^{61}$

Den letzten Jenseitsführertypus vertritt ein Mensch, der mit dem Seher auf irgendeine Weise verwandt ist. Es kann sich um eine Blutsverwandtschaft (ein Familienmitglied) oder um eine Geistesverwandtschaft (z. Bsp. zu einem Mitbruder) handeln. Da das geistige Band den Tod überlebt, interessierten sich die Mönche eines Ordens oft für die ihrem Orden vorbehaltenen Gebiete im Jenseits oder für das Schicksal ihrer verstorbenen Konfratres, auf deren Hilfe sie auf dem eigenen Weg ins Jenseits nach ihrem Tod hofften. Ziel dieser Visionen war auch die Verherrlichung einer Ordensgemeinschaft sowie die moralische Erziehung ihrer Mitglieder. ${ }^{62}$ Auffallend ist, dass in den Visionsberichten Erwähnungen über Konkurrenzorden fehlen. Falls diese jedoch trotzdem auftauchen, haben sie meistens eine negative Konnotation. ${ }^{63}$ Dementsprechend wäre es unwahrscheinlich, dass ein Zisterzienser einem Benediktiner im Jenseits begegnen würde.

57 Condat, heute Saint-Claude in Franche-Cómte. Die Vision ist Bestandteil des gemeinsamen Lebenslaufes dieser drei Heiligen (Vita patrum Iurensium Romani, Lupicini, Eugendi). Zum hl. Romanus und Lupicinus siehe BBKL (XVI, col. 1376-1377, s. v. Romanus und Lupicinus).

58 Visio Heinrici de Aharin, (p. 60): Sum quippe Apostolus Christi iacobus, quem ideo adiutorem habere meruisti quoniam meam ad memoriam te iturum spopondisti.

59 Thurkill gab gerne Almosen und beherbergte Pilger. Zur Julianus-Legende siehe De Gaiffier (1945: pp. 145-219). Zum heiligen Domninus von Fidenza siehe BS (IV, col. 809-811); AASS (Oct. IV, 1780, pp. 987-993).

60 Thurkill war vermutlich als Pilger in Santiago de Compostela; Schmidt (1987: p. 82, Anm. 20).

61 Am Ende berücksichtigt der Visionsbericht auch die englische Märtyrerin Osytha, die Patronin der gleichnamigen Gemeinde und des Konvents in Essex. Schmidt (1987: p. 10) vermutet eine Abfassung des Visionsberichtes durch einen Kanonikus dieser Kirche.

62 Vgl. Dinzelbacher (1981: p. 218).

63 Vgl. Anm. 44. 
Der Augustiner-Chorherr aus Lothringen wird von einem Augustiner Gilbaudus ins Paradies geführt, in dem er dem Visionär $u$. a. die Jenseitswohnungen seiner Mitbrüder zeigt. ${ }^{64}$ Einem ungenannten Zisterzienser erscheinen in seiner Vision, die aus der Mitte des 12. Jh. stammt, ebenso nur Mitglieder seines Ordens, unter denen er auch seinen besten Freund erblickt. ${ }^{65}$ Ein anonymer Pulsanenser-Mönch wird durch eine ihm aus der Vergangenheit bekannte Person geleitet. ${ }^{66}$ In der anderen Welt erblickt er verstorbene Mitbrüder und einer von ihnen bittet ihn um Fürsprache bei dem Klostergründer Johannes von Matera. ${ }^{67}$ Auch der schon erwähnte Mönch Barontus trifft vor dem ersten Paradiestor die Gruppe seiner Mitbrüder, die aus ihrer Mitte den Bruder Framnoaldus auswählen, um den Seher auf der Rückreise zu begleiten. Im Gegenzug verspricht Barontus diesem die regelmäßige Pflege seines Grabes samt dem Gebet zu dessen Seelenheil. ${ }^{68}$

Auch die Familienbeziehungen, zumindest nach den Visionsberichten, bleiben nach dem Tod bewahrt. Zuzeiten erfolgt in der anderen Welt eine Begegnung von Eltern mit ihren Kindern oder von Eheleuten. ${ }^{69}$ In einer durch Petrus von Cornwall ( $\uparrow 1221$ ) aufgezeichneten Vision begleitet seinen Vater Ailsi (Aethelsige) der verstorbene Sohn Paganus. ${ }^{70}$ Es kommt zu einer ähnlichen Begegnung wie in der Aeneis (VI,684ff.), nur dass die Rollen vertauscht sind. Während Anchises seinem Sohn den zukünftigen Ruhm vorhersagt (VI,888-892), gibt Paganus seinem Vater dessen bevorstehenden Tod bekannt. ${ }^{71}$ Seiner ganzen Familie begegnet im Jenseits Merchdeof, der nach dem Ableben seiner ersten Frau wieder geheiratet hatte. ${ }^{72}$ In Begleitung seiner verstorbenen Kinder kommt der Seher zuerst vor ein Gottesgericht, später zu seiner Gattin, die jedoch kein Verständnis für Merchdeofs neue Ehe zeigt. Ihren Zorn müssen die Kinder mildern, sodass dem Visionär zum Schluss erlaubt ist, in seinen Körper wieder zurückzukehren. ${ }^{73}$

64 Visio Augustinensis canonici de Lorraine (p. 143): ... quidam frater noster Gilbaudus nomine quem cognouit, qui multa ei de fratribus nostris intimauit, ibique loca quorundam fratrum nostrorum ostendit...

65 Visio Augustinensis canonici de Lorraine (p. 89): ... recognovit unum, quem in carne viventem pre ceteris dilexerat, ideoque glorie eius plurimum congaudebat.

66 Visio Pulsanensis monachi (col. 51F): Contigit... assistere sibi in visione quamdam quam in seculo notam habuerat personam, monentem ac precipientem sibi, ut eum sequeretur.

67 Die Vision ist in der Vita Ioannis a Mathera aufgezeichnet.

68 Visio Baronti (p. 389): Si istum fratrem ad monasterium reducis, per singulos dominicos tuum sepulchrum scopis munditiam adhibeat et super ipsum Miserere mei, Deus per ordinem usque ad finem decantet.

69 Die Vision Karls III. verbindet vier Generationen der Karolinger (siehe Visio Karoli Crassi). Seinem Sohn begegnet im Jenseits der Seher Ailsi und ein Laienbruder aus Clairvaux (siehe Visio unius fratris Claravallensis). Der Bauer Thurkill findet in der anderen Welt seinen Vater. Merchdeof begegnet in einer Vision allen verstorbenen Mitgliedern seiner Familie. Die Mutter Guiberts von Nogent hilft ihrem verstorbenen Mann, den sie in einer Vision erblickt (siehe Guibert von Nogent, De vita sua I,18). Und Gottschalk wird Zeuge der Wiederbegegnung eines Ehepaares im Jenseits.

70 Die Vision ist in Petrus' Sammlung Liber revelationum zu finden. Nicht ohne Interesse ist, dass Petrus von Cornwall der Enkel des Visionärs war.

71 Visio Ailsi (p. 212): Oportet enim te nunc redire..., ubi de curso modico tempore, apponeris ad patres tuos, finiens uitam tuam in senectute bona.

72 Die Vision gehört zum Gedicht De abbatibus des angelsächsischen Mönches Aethelwulf (Aedilvulf) aus dem Anfang des 9. Jh.

73 Visio Merchdeofi (v. 53-59; 65-66): Illa sed ingeminans connexum carceris umbras / Iussit adire virum, donec iam 
Übrig bleiben noch 8 meistens kurz gefasste Visionsberichte, die die Figur eines Jenseitsbegleiters ohne weitere Einzelheiten aufführen. Er wird einfach nur als ductor, (Visio Bernoldi, Visio Ratisponensis mendici, Visio Bosonis, Visio Anselmi Cantuariensis), bzw. quidam homo (Visio presbyteri de terra Anglorum, Visio cuiusdam pauperculae mulieris) oder vir quidam (Visio puellae monasterii beatae Radegundis, Visio Otlohi) erwähnt.

Die Aufgaben, die ein Jenseitsführer gegenüber dem Seher in seiner Vision übernahm, sowie die Beziehung zwischen dem Visionär und seinem Begleiter verdeutlichen die verschiedenen in den Visionstexten belegten Bezeichnungen, mit denen der Begleiter ins Jenseits charakterisiert wird. Neben der üblichen Bezeichnung als ductor findet dieser sich hierin auch als ostensor (Visio Wettini), praevius (Visio puellae monasterii beatae Radegundis), dominus (Visio Maximi, Tnugdali, Visio monachi de cenobio sancti Vedasti), dux (Visio Johannis Leodiensis), protector (Visio Agusti), tutor (Visio monachi de cenobio sancti Vedasti), auxiliator (Visio Gunthlaci) oder als magister (Visiones Elisabeth Schonaugiensis) erwähnt.

Die vorausgehende Darstellung hat gezeigt, dass in den untersuchten Visionsberichten, deren Entstehung sich über einen Zeitraum von 7 Jahrhunderten erstreckt, drei Grundtypen von Jenseitsführern in Erscheinung treten: Engel, Heilige und Verwandte.

Den Typus des Engels, der in den mittelalterlichen Visionen am häufigsten als Begleiter vorkommt, hat für diese Rolle schon die ältere literarische Tradition, vor allem die Bibel, vorherbestimmt. Auch die Auswahl eines konkreten Heiligen als Führer ins Jenseits ist nicht zufällig erfolgt. Dieser repräsentiert in den Visionsberichten meistens einen Orts- oder Namenspatron, der dem Seher und seinem sozialen Umfeld sehr gut bekannt ist. Die Visionen, in denen der Begleiter zu den verstorbenen Familienmitgliedern des Sehers - entweder durch Blutsverwandtschaft oder im übertragenen Sinne in Form einer geistigen Verwandtschaft - gehört, zeigen, ähnlich wie viele Erzählungen über Wiedergänger, dass in der Vorstellungswelt der mittelalterlichen Gesellschaft die sozialen Beziehungen auch nach dem Tod beibehalten wurden.

Alle im untersuchten Quellenmaterial vorkommenden Jenseitsführer fasst in chronologischer Übersicht folgende Tabelle zusammen.

\section{Liste der Visionen mit der Figur eines Jenseitsführers}

\begin{tabular}{|l|l|l|l|l|}
\hline & Datum & Vision & Führer & Quelle \\
\hline 1. & 6. Jh. & Visio Eugendi & $\begin{array}{l}\text { sancti Romanus ac Lupici- } \\
\text { nus patres }\end{array}$ & $\begin{array}{l}\text { Vita patrum Iurensium Romani, Lupi- } \\
\text { cini, Eugendi, 2-3 }\end{array}$ \\
\hline 2. & 6. Jh. & Visio Salvii & duo angeli; comites mei & $\begin{array}{l}\text { Gregor von Tours: Libri Historiarum } \\
\text { X, VII,1 }\end{array}$ \\
\hline
\end{tabular}

crimina cuncta / flammis obsorbtus nimium persolvat in atris. Plantis at strati ruitabant pignora matris, / „Perque dei nomen“, rogitant, „miserere, precamur, / Vel saltim liceat corpus visitare marito, / Solvere sicque sua mereatur crimina vivens. "... Hinc iterum adductus natis comitantibus almis / Pervenit ad corpus, ... 
Führer durch das mittelalterliche Jenseits - eine Übersicht

\begin{tabular}{|c|c|c|c|c|}
\hline & Datum & Vision & Führer & Quelle \\
\hline 3. & vor 588 & $\begin{array}{l}\text { Visio puellae mo- } \\
\text { nasterii beatae } \\
\text { Radegundis }\end{array}$ & vir quidam; praevius & $\begin{array}{l}\text { Gregor von Tours: Libri Historiarum } \\
X, \mathrm{VI}, 29\end{array}$ \\
\hline 4. & $\begin{array}{l}\text { Anfang } \\
\text { des 7. Jh. }\end{array}$ & Visio Agusti & $\begin{array}{l}\text { Dominus Ihesus Christus; } \\
\text { benedicens rex }\end{array}$ & $\begin{array}{l}\text { Vitas sanctorum patrum Emereten- } \\
\text { sium, } 1,1\end{array}$ \\
\hline 5. & $633 ?$ & Visio Fursei & tres caelicolae; angeli & Vita sancti Fursei, 2-16 \\
\hline 6. & 7. Jh. & $\begin{array}{l}\text { Visio Sadalber- } \\
\text { gae }\end{array}$ & $\begin{array}{l}\text { avis miri candoris ac } \\
\text { splendore nimio fulgens; } \\
\text { beatus Ansericus }\end{array}$ & $\begin{array}{l}\text { Vita Sadalbergae abbatissae Laudu- } \\
\text { nensis, } 26\end{array}$ \\
\hline 7. & $678 / 9$ & Visio Baronti & $\begin{array}{l}\text { sanctus Rafahel; beatus } \\
\text { Petrus; frater Framnoaldus }\end{array}$ & Visio \\
\hline 8. & $692 / 6$ & Visio Drycthelmi & ductor lucidus aspectu & $\begin{array}{l}\text { Beda Venerabilis: Historia ecclesiasti- } \\
\text { ca gentis Anglorum, V,12 }\end{array}$ \\
\hline 9. & vor 695 & Visio Maximi & angelus & Valerius von Bierzo: Opuscula, 17-19 \\
\hline 10. & vor 695 & Visio Bonelli & angelus & Valerius von Bierzo: Opuscula, 20-22 \\
\hline 11. & vor 695 & Visio Baldarii & $\begin{array}{l}\text { tres splendidissimae co- } \\
\text { lumbae }\end{array}$ & Valerius von Bierzo: Opuscula, 23-24 \\
\hline 12. & ca 716 & $\begin{array}{l}\text { Visio Wenlocen- } \\
\text { sis monachi }\end{array}$ & $\begin{array}{l}\text { magnae claritatis et splen- } \\
\text { doris angeli }\end{array}$ & HI. Bonifatius: Epistola 10 \\
\hline 13. & 8. Jh. & $\begin{array}{l}\text { Visio cuiusdam } \\
\text { feminae }\end{array}$ & angelici duces & HI. Bonifatius: Epistola 115 \\
\hline 14. & 8. Jh. & Visio Guthlaci & sanctus Bartholomaeus & $\begin{array}{l}\text { Vita sancti Guthlaci auctore Felice, } \\
31-33\end{array}$ \\
\hline 15. & $803 / 21$ & Visio Aethelwulfi & ductor candidus & Aethelwulf: Carmen 22 \\
\hline 16. & 9. Jh. & Visio Merchdeofi & pueri; pignora & Aethelwulf: Carmen 11 \\
\hline 17. & 824 & Visio Wettini & $\begin{array}{l}\text { angelus incredibili splen- } \\
\text { dens pulchritudine }\end{array}$ & Heito von Reichenau: Visio Wettini \\
\hline 18. & ca 839 & $\begin{array}{l}\text { Visio presbyteri } \\
\text { de terra Anglo- } \\
\text { rum }\end{array}$ & quidam homo & $\begin{array}{l}\text { Prudentius von Troyes: Annales, } \\
\text { anno } 839\end{array}$ \\
\hline 19. & $818 / 840$ & $\begin{array}{l}\text { Visio cuiusdam } \\
\text { pauperculae } \\
\text { mulieris }\end{array}$ & $\begin{array}{l}\text { quidam homo in monachi- } \\
\text { co habitu }\end{array}$ & Visio \\
\hline 20. & $858 ?$ & Visio Eucherii & angelus, eius ductor & Capitularia, Quierzy 858 \\
\hline 21. & bis 865 & Visio Anskarii & $\begin{array}{l}\text { sanctus Petrus et lo- } \\
\text { hannes Baptista }\end{array}$ & $\begin{array}{l}\text { Rimbert von Bremen: Vita sancti } \\
\text { Anskarii, } 3\end{array}$ \\
\hline 22. & vor 872 & Visio Senecae & $\begin{array}{l}\text { vir vestibus albis, fulgidus } \\
\text { aspectu }\end{array}$ & $\begin{array}{l}\text { Alcuin von York: Versus de sanctis } \\
\text { Euboricensis ecclesiae, 1601-1657 }\end{array}$ \\
\hline 23. & 878 & Visio Bernoldi & ductor; unus homo & $\begin{array}{l}\text { Hinkmar von Reims: De Visione } \\
\text { Bernoldi Presbyteri }\end{array}$ \\
\hline 24. & 9. Jh. & Visio Rotcharii & $\begin{array}{l}\text { angelus nimio splendore } \\
\text { coruscus }\end{array}$ & Visio \\
\hline 25. & $888 / \mathrm{ca} 900$ & $\begin{array}{l}\text { Visio Karoli } \\
\text { Crassi }\end{array}$ & ductor candidissimus & $\begin{array}{l}\text { Wilhelm von Malmesbury: Gesta } \\
\text { regum Anglorum, II, } 111\end{array}$ \\
\hline 26. & 10. Jh. & Visio Dunstani & $\begin{array}{l}\text { senex niveo candore ve- } \\
\text { stitus }\end{array}$ & $\begin{array}{l}\text { Byrhtferth von Ramsey: Sancti Dun- } \\
\text { stani vita, } 1\end{array}$ \\
\hline 27. & 11. Jh.? & Visio Anselli & Salvator; dyabolus & Visio \\
\hline 28. & $1011 / 1012$ & $\begin{array}{l}\text { Visio monachi de } \\
\text { cenobio sancti } \\
\text { Vedasti }\end{array}$ & $\begin{array}{l}\text { dominus sanctus Michael; } \\
\text { pacis et lucis Michael an- } \\
\text { gelus; tutor serenissimus }\end{array}$ & $\begin{array}{l}\text { Hugo von Flavigny: Chronicon, II, } \\
\text { anno } 1011\end{array}$ \\
\hline
\end{tabular}


Führer durch das mittelalterliche Jenseits - eine Übersicht

\begin{tabular}{|c|c|c|c|c|}
\hline & Datum & Vision & Führer & Quelle \\
\hline 29. & $1011 / 1012$ & $\begin{array}{l}\text { Visio alterius } \\
\text { monachi de } \\
\text { cenobio sancti } \\
\text { Vedasti }\end{array}$ & angelus, sanctus Michael & $\begin{array}{l}\text { Hugo von Flavigny: Chronicon, II, } \\
\text { anno } 1012\end{array}$ \\
\hline 30. & $11 \mathrm{Jh}$. & Visio Votifragi & $\begin{array}{l}\text { B. Petrus apostolus splen- } \\
\text { didus et coruscans }\end{array}$ & $\begin{array}{l}\text { Petrus Damiani: De variis miraculosis } \\
\text { narrationibus, } 9\end{array}$ \\
\hline 31. & 1069 & Visio Earnani & $\begin{array}{l}\text { sanctus Cuthbertus; sanc- } \\
\text { tus Oswaldus }\end{array}$ & $\begin{array}{l}\text { Symeon von Durham: Historia Dunel- } \\
\text { mensis ecclesiae, III, } 16\end{array}$ \\
\hline 32. & \begin{tabular}{|l|} 
ca $1052-$ \\
1056 \\
\end{tabular} & Visio Otlohi & (demones); quidam vir & $\begin{array}{l}\text { Otloh von St. Emmeram: Liber visio- } \\
\text { num, } 4\end{array}$ \\
\hline 33. & vor 1070 & $\begin{array}{l}\text { Visio Ratispo- } \\
\text { nensis mendici }\end{array}$ & ductor & $\begin{array}{l}\text { Otloh von St. Emmeram: Liber visio- } \\
\text { num, } 11\end{array}$ \\
\hline 34. & vor 1070 & Visio Isaaci & beatus Guntharius & $\begin{array}{l}\text { Otloh von St. Emmeram: Liber visio- } \\
\text { num, } 14\end{array}$ \\
\hline 35. & $1093 / 1096$ & Visio Bosonis & ductor & $\begin{array}{l}\text { Symeon von Durham: Historia Dunel- } \\
\text { mensis ecclesiae, IV } 9\end{array}$ \\
\hline 36. & 11. Jh. & $\begin{array}{l}\text { Visio Anselmi } \\
\text { Cantuariensis }\end{array}$ & ductor & $\begin{array}{l}\text { Eadmer von Canterbury: De vita et } \\
\text { conversatione Anselmi archiepiscopi } \\
\text { Cantuariensis, } 31\end{array}$ \\
\hline 37. & $1100-1106$ & $\begin{array}{l}\text { Visio Augusti- } \\
\text { nensis canonici } \\
\text { de Lorraine }\end{array}$ & $\begin{array}{l}\text { angelus; quidam frater } \\
\text { noster Gilbaudus }\end{array}$ & Visio \\
\hline 38. & 1117 & Visio Alberici & $\begin{array}{l}\text { avis candida, columbe } \\
\text { similis; beatus Petrus } \\
\text { apostolus ac duo angeli, } \\
\text { Hemmanuel et Heloy }\end{array}$ & Visio \\
\hline 39. & ca 1120 & Visio Raheri & $\begin{array}{l}\text { vir quidam regiam majes- } \\
\text { tatem vultu praeferens, } \\
\text { mirae pulchritudinis et } \\
\text { imperialis auctoritatis; } \\
\text { Bartholomaeus, apostolus } \\
\text { Jesu Christi }\end{array}$ & $\begin{array}{l}\text { Cartae ad prioratum S. Bartholomaei } \\
\text { in Smithfelde, } 1\end{array}$ \\
\hline 40. & 1126 & $\begin{array}{l}\text { Visio simplicis } \\
\text { Orm }\end{array}$ & $\begin{array}{l}\text { vir venerabilis, Michael } \\
\text { archangelus }\end{array}$ & $\begin{array}{l}\text { Sigar von Newbald: Vita et visio et } \\
\text { finis simplicis Orm }\end{array}$ \\
\hline 41. & 1130 & $\begin{array}{l}\text { Visio Heinrici de } \\
\text { Aharin }\end{array}$ & $\begin{array}{l}\text { senior quidam pulchre } \\
\text { visionis, mire auctoritatis; } \\
\text { apostolus lacobus }\end{array}$ & Miraculum s. lacobi \\
\hline 42. & vor 1139 & $\begin{array}{l}\text { Visio Pulsanensis } \\
\text { monachi }\end{array}$ & $\begin{array}{l}\text { quedam, quam in seculo } \\
\text { notam habuerat, persona }\end{array}$ & Vita loannis a Mathera, 5,39-41 \\
\hline 43. & vor 1139 & $\begin{array}{l}\text { Visio alterius } \\
\text { Pulsanensis } \\
\text { monachi }\end{array}$ & $\begin{array}{l}\text { quidam splendidissimus } \\
\text { Angelus; (teterrimus \& } \\
\text { multum horribilis spiritus } \\
\text { malignus) }\end{array}$ & Vita loannis a Mathera, $6,45-51$ \\
\hline 44. & 1139 & $\begin{array}{l}\text { Visio Mathei } \\
\text { Albanensis }\end{array}$ & $\begin{array}{l}\text { vir reverendi vultus, multa } \\
\text { ac venusta tam capitis } \\
\text { quam vestium albedine } \\
\text { decorus ... de incolis eremi }\end{array}$ & $\begin{array}{l}\text { Petrus Venerabilis: De miraculis libri } \\
\text { duo, } 11,21\end{array}$ \\
\hline 45. & 12. Jh. & Visio Ailsi & filius Paganus & $\begin{array}{l}\text { Peter von Cornwall: Liber revelatio- } \\
\text { num, } 1,6\end{array}$ \\
\hline 46. & $1143 / 7$ & Visio Guillelmi & vir splendidus; ductor & $\begin{array}{l}\text { Helinand von Froidmont: Chronicon, } \\
\text { anno } 1146\end{array}$ \\
\hline
\end{tabular}


Führer durch das mittelalterliche Jenseits - eine Übersicht

\begin{tabular}{|c|c|c|c|c|}
\hline & Datum & Vision & Führer & Quelle \\
\hline 47. & $1146-1147$ & $\begin{array}{l}\text { Visio militis } \\
\text { Owein }\end{array}$ & $\begin{array}{l}\text { (deamones); duo velut } \\
\text { archiepiscopi }\end{array}$ & $\begin{array}{l}\text { H. von Saltrey: Tractatus de Purgato- } \\
\text { rio S. Patricii }\end{array}$ \\
\hline 48. & 1147 & $\begin{array}{l}\text { Visio Johannis } \\
\text { Leodiensis }\end{array}$ & $\begin{array}{l}\text { beatus Laurentius; sanc- } \\
\text { tus Mauritius }\end{array}$ & Visio de statu animarum \\
\hline 49. & 1149 & Visio Tnugdali & angelus & Visio \\
\hline 50. & $1152 / 1164$ & $\begin{array}{l}\text { Visiones Elisa- } \\
\text { beth Schonau- } \\
\text { giensis }\end{array}$ & angelus & $\begin{array}{l}\text { Elisabeth von Schönau: Libri visio- } \\
\text { num tres; Liber viarum Dei }\end{array}$ \\
\hline 51. & $\begin{array}{l}\text { vor } \\
1153 / 1161 ?\end{array}$ & Visio Gunthelmi & $\begin{array}{l}\text { sanctus Benedictus; sanc- } \\
\text { tus Raphael archangelus }\end{array}$ & Visio \\
\hline 52. & $1159-1170$ & Visio Walteri & duo uiri preclari & $\begin{array}{l}\text { Jocelyn von Furness: Vita sancti } \\
\text { Waldevi, 100-107 }\end{array}$ \\
\hline 53. & $\begin{array}{l}\text { 2. Hälfte } \\
\text { des 12. Jh. }\end{array}$ & $\begin{array}{l}\text { Visio Cistercien- } \\
\text { sis fratris }\end{array}$ & $\begin{array}{l}\text { duo cives illius superceles- } \\
\text { tis Iherusalem; angeli }\end{array}$ & Visio \\
\hline 54. & bis 1170 & $\begin{array}{l}\text { Visio Godrici de } \\
\text { Finchale }\end{array}$ & $\begin{array}{l}\text { Jesus Nazaraenus; coeli } \\
\text { clavicularius Petrus; Jo- } \\
\text { hannes Baptista }\end{array}$ & $\begin{array}{l}\text { Reginald von Durham: Libellus de } \\
\text { vita et miraculis s. Godrici, } 150\end{array}$ \\
\hline 55. & ca 1170 & $\begin{array}{l}\text { Visio Christinae } \\
\text { Mirabilis }\end{array}$ & ministri lucis; angeli Dei & $\begin{array}{l}\text { Thomas von Cantimpré: Vita s. } \\
\text { Christinae Mirabilis virginis, } 3\end{array}$ \\
\hline 56. & nach 1172 & $\begin{array}{l}\text { Visio cuiusdam } \\
\text { militis in Britan- } \\
\text { nia }\end{array}$ & duo angeli & Vita beati Petri Abrincensis, 10-11 \\
\hline 57. & vor 1178 & $\begin{array}{l}\text { Visio cuiusdam } \\
\text { abbatis }\end{array}$ & beatus Bernhardus & $\begin{array}{l}\text { Herbert von Clairvaux: Liber miracu- } \\
\text { lorum, } 6\end{array}$ \\
\hline 58. & vor 1178 & $\begin{array}{l}\text { Visio monachi de } \\
\text { Italia }\end{array}$ & ductores & $\begin{array}{l}\text { Herbert von Clairvaux: Liber miracu- } \\
\text { lorum, } 56\end{array}$ \\
\hline 59. & vor 1180 & $\begin{array}{l}\text { Visiones Aupes } \\
\text { de Cudot }\end{array}$ & angelus; virginis ductor & Vita anonyma \\
\hline 60. & 12. Jh. & Visio Raineri & $\begin{array}{l}\text { angelicae venustatis qui- } \\
\text { dam juvenis }\end{array}$ & $\begin{array}{l}\text { Reiner von Lüttich: Lacrymarum } \\
\text { libelli tres, I,4 }\end{array}$ \\
\hline 61. & 12. Jh. & $\begin{array}{l}\text { Visio Cistercien- } \\
\text { sis novicii }\end{array}$ & $\begin{array}{l}\text { Maria, mater Domini Ihesu } \\
\text { Christi }\end{array}$ & De novicio \\
\hline 62. & 1189 & $\begin{array}{l}\text { Visio Gode- } \\
\text { schalci }\end{array}$ & duo angeli & Visio \\
\hline 63. & $1195 / 6$ & $\begin{array}{l}\text { Visio monachi in } \\
\text { Vacellis claustro }\end{array}$ & angelus & Visio \\
\hline 64. & 1196 & $\begin{array}{l}\text { Visio Edmundi } \\
\text { monachi de } \\
\text { Eynsham }\end{array}$ & Nicholaus; ductor & Visio \\
\hline 65. & ca 1200 & $\begin{array}{l}\text { Visio Willelmi de } \\
\text { Liesnes }\end{array}$ & supprior Robertus & $\begin{array}{l}\text { Peter von Cornwall: Liber revelatio- } \\
\text { num, } 1,204\end{array}$ \\
\hline 66. & ca 1200 & Visio Zachariae & $\begin{array}{l}\text { angelus Barachias; perso- } \\
\text { na honesta tunica stricta } \\
\text { uestita }\end{array}$ & $\begin{array}{l}\text { Peter von Cornwall: Liber revelatio- } \\
\text { num, I,8 }\end{array}$ \\
\hline 67. & ca 1200 & $\begin{array}{l}\text { Visio canonici } \\
\text { regularis }\end{array}$ & angelus & $\begin{array}{l}\text { Peter von Cornwall: Liber revelatio- } \\
\text { num, I,185 }\end{array}$ \\
\hline 68. & ca 1200 & $\begin{array}{l}\text { Visio fratris } \\
\text { venerabilis }\end{array}$ & angelico ducatu, angelus & $\begin{array}{l}\text { Peter von Cornwall: Liber revelatio- } \\
\text { num, II,899 }\end{array}$ \\
\hline 69. & 1206 & Visio Thurkilli & $\begin{array}{l}\text { sanctus lulianus; sanctus } \\
\text { Dompninus; sanctus Mi- } \\
\text { chael archangelus }\end{array}$ & Visio \\
\hline
\end{tabular}




\title{
Bibliographie
}

\section{Abkürzungen}

\author{
AASS Acta sanctorum \\ BBKL Biographisch-Bibliographisches Kirchenlexikon \\ BS Bibliotheca Sanctorum \\ FRB Fontes rerum Bohemicarum \\ LexMa Lexikon des Mittelalters \\ MGH Monumenta Germaniae historica \\ ES Epistolae selectae \\ LL Leges \\ PPL Poetae latini \\ QG Quellen zur Geistesgeschichte des Mittelalters \\ SS Scriptores \\ SSRM Scriptores rerum Merovingicarum \\ PL Migne, Patrologia Latina \\ RS Rolls Series, Rerum Britannicarum medii aevi scriptores \\ SC Sources chrétiennes \\ THAT Theologisches Handwörterbuch zum Alten Testament
}

\section{Subsidia}

Biographisch-Bibliographisches Kirchenlexikon, XVI (1999). Herzberg: Traugott Bautz.

Bibliotheca Sanctorum, IV (1964). Roma: Istituto Giovanni XXIII della Pontificia Università Lateranense.

Davidson, G. (1967). A Dictionary of Angels: Including the Fallen Angels. New York: The Free Press. Jenni, E., \& Westermann, C. (Eds.). (1978). Theologisches Handwörterbuch zum Alten Testament, I. München: Chr. Kaiser Verlag - Zürich: Theologischer Verlag.

Krauss, H. (2001). Kleines Lexikon der Engel: Von Ariel bis Zebaoth. München: C. H. Beck. Lexikon des Mittelalters, CD-ROM Ausgabe (2000). Stuttgart - Weimar: J. B. Metzler.

\section{Quellen}

\section{Ausgabe der Visionen gemäß ihrer Folge in der Tabelle}

1. Krusch, B. (Ed.). (1896). Vita patrum Iurensium Romani, Lupicini, Eugendi (MGH, SSRM, 3; pp. 125-166). Hannoverae: Impensis Bibliopolii Hahniani.

2.-3. Krusch, B. (Ed.). (1951). Gregorii episcopi Turenensis libri historiarum X (MGH, SSRM, I,1). Hannoverae: Impensis Bibliopolii Hahniani.

4. Garvin, J. N. (Ed.). (1946). The Vitas sanctorum patrum emeretensium: Text and Translation, with an Introduction and Commentary. Washington: Catholic University of America Press. 
5. Carozzi, C. (1994). Le voyage de l'âme dans l'au-delà d'après la littérature latine (Ve-XIIIe siècle) (pp. 677-692). Rome: École française de Rome.

6. Krusch, B. (Ed.) (1910). Vita Sadalbergae abbatissae Laudunensis (MGH, SSRM, V; pp. 40-66). Hannoverae: Impensis Bibliopolii Hahniani.

7. Krusch, B., \& Levison, W. (Eds.). (1910). Visio Baronti monachi Longoretensis (MGH, SSRM, V; pp. 368-394). Hannoverae et Lipsiae: Impensis Bibliopolii Hahniani.

8. Lapidge, M. (Ed.), Monat, P., \& Robin, P. (Transl.). (2005). Beda Venerabilis: Historia ecclesiastica gentis Anglorum (SC, 489-91). Paris: Cerf.

9.-11. Migne, J. P. (Ed.). (1863). Sancti Valerii abbatis Opuscula (PL, 87; pp. 421-458). Paris: J. P. Migne.

12.-13. Tangl, M. (Ed.). (1916). Die Briefe des heiligen Bonifatius und Lullus (MGH, ES, I). Berolini: Apud Weidmannos.

14. Colgrave, B. (Ed.). (1956). Felix's Life of Saint Guthlac: Introduction, Text, Translation and Notes. Cambridge: Cambridge University Press.

15.-16. Dümmler, E. (Ed.). (1881). Aedilvulf Carmen (MGH, PPL, I; pp. 582-604). Berolini: Apud Weidmannos.

17. Dümmler, E. (Ed.). (1884). Walahfridi Strabi Carmina (MGH, PPL, II; pp. 259-473). Berolini: Apud Weidmannos.

18. Pertz, G. H. (Ed.). (1826). Annalium Bertinianorum pars secunda auctore Prudentio, Trecensi episcopo (MGH, SS, I; pp. 429-454). Hannoverae: Impensis Bibliopolii Hahniani.

19. Houben, H. (Ed.). (1976). Visio cuiusdam pauperculae mulieris: Überlieferung und Herkunft eines frühmittelalterlichen Visionstextes (mit Neuedition). Zeitschrift für Geschichte des Oberrheins, 124, 31-42.

20. Hartmann, W. (Ed.). (1984). Die Konzilien der karolingischen Teilreiche 843-859 (MGH, LL, Concilia, III). Hannoverae: Impensis Bibliopolii Hahniani.

21. Pertz, G. H. (Ed.). (1829). Vita s. Anskarii (MGH, SS, II; pp. 683-725). Hannoverae: Impensis Bibliopolii Hahniani.

22. Dümmler, E. (Ed.). (1881). Alcuini carmina (MGH, PPL, I; pp. 160-351). Berolini: Apud Weidmannos.

23. Migne, J. P. (Ed.). (1852). Hincmarus Rhemenensis: De Visione Bernoldi Presbyteri. In Idem (Ed.), Hincmari Rhemenensis archiepiscopi opera omnia (Tomus Prior; PL, 125; col. 1115-1119). Paris: J. P. Migne.

24. Wattenbach, W. (Ed.). (1875). Aus Petersburger Handschriften. Anzeiger für Kunde der deutschen Vorzeit, 22, 72-74.

25. Hardy, T. D. (Ed.). (1840). Willelmi Malmesbiriensis monachi Gesta regum Anglorum atque historia novella (Vol. I). Londoni: Sumptibus Societatis.

26. Migne, J. P. (Ed.). (1853). Bridfertus Ramesiensis monachus: Sancti Dunstani vita (PL, 139; col. 1424-1456). Paris: J. P. Migne.

27. Leclercq, J. (Ed.). (1969). Une redaction en prose de la „Visio Anselli” dans un manuscrit de Subiaco. Benedictina, 1, 188-195.

28.-29. Pertz, G. H. (Ed.). (1848). Chronicon Hugonis monachi Virdunensis et Divionensis, abbatis Flaviniacensis (MGH, SS, VIII; pp. 288-502). Hannoverae: Impensis Bibliopolii Hahniani. 
30. Migne, J. P. (Ed.). (1853). Petrus Damiani: De variis miraculosis narrationibus. In Idem (Ed.), S. Petri Damiani opera omnia. Tomus secundus (PL, 145; col. 571-590). Paris: J. P. Migne.

31., 35. Arnold, T. (Ed.). (1965, reprint). Symeonis monachi Historia Dunelmensis ecclesiae. In Idem (Ed.), Symeonis monachi opera omnia. (Tom. I; RS 75/1). Wiesbaden: Kraus Reprint.

32.-34. Schmidt, P. G. (Ed.). (1989). Otloh von St. Emmeram: Liber Visionum (MGH, QG, XIII). Weimar: Hermann Böhlaus Nachfolger.

36. Rule, M. (Ed.). (1884). Eadmeri Historia Novorum in Anglia, et opuscula duo de Vita sancti Anselmi et quibusdam miraculis ejus (RS, 81; pp. 305-424). London: Longman and Co.

37. Staats, S. (Ed.). (1995). Vision of an Augustinian Canon in Lorraine: Echoes of the Investiture Conflict in the Diocese of Metz at the Beginning of the Twelfth Century. Analecta Bollandiana, $113,127-146$.

38. Schmidt, P. G. (Ed.). (1997). Visio Alberici: Die Jenseitswanderung des neunjährigen Alberich in der vom Visionär um 1127 in Monte Cassino revidierten Fassung. Stuttgart: Steiner.

39. Dugdale, W. (Ed.). (1849). Cartae ad prioratum S. Bartholomaei in Smithfelde. In Idem (Ed.), Monasticon Anglicanum (Vol. VI/1; pp. 291-296). London: T. G. March.

40. Farmer, H. (Ed.). (1957). The Vision of Orm. Analecta Bollandiana, 75, 72-82.

41. Plötz, R., \& Röckelein, H. (1999). Die Vision des Heinrich von Ahorn und das Kloster St. Georgenberg. In K. Herbers (Ed.), Stadt und Pilger: Soziale Gemeinschaften und Heiligenkult (pp. 29-68). Tübingen: Gunter Narr Verlag.

42.-43. Acta Sanctorum Full-Text Database (2001). Vita Ioannis a Mathera auctore anonymo (AASS, Jun. IV, 1707, pp. 41-58). Cambridge: Chadwyck-Healey.

44. Migne, J. P. (Ed.). Petrus Venerabilis: De miraculis libri duo. In Idem (Ed.), Petri Venerabilis abbatis Cluniacensis noni opera omnia (PL, 189, col. 851-954). Paris: J. P. Migne.

45. Easting, R., \& Sharpe, R. (Eds.). (2013). Peter of Cornwall's Book of Revelations. Oxford - Toronto: Pontifical Institute of Mediaeval Studies.

46. Migne, J. P. (Ed.). (1863). Helinandi Frigidi montis monachi Chronicon. In Idem (Ed.), Helinandi Frigidi montis monachi necnoc Guntheri Cisterciensis opera omnia (PL, 212; col. 771-1081). Paris: J. P. Migne.

47. Migne, J. P. (Ed.). (1855). Henrici Salteriensis Tractatus de Purgatorio Sancti Patricii Hibernorum apostoli (PL, 180; col. 973-1004). Paris: J. P. Migne.

48. Migne, J. P. (Ed.). (1855). Joannes monachus s. Laurentii Leodiensis: Visio status animarum post mortem (PL, 180; col. 177-186). Paris: J. P. Migne.

49. Pfeil, B. (Ed.). (1999). Die „Vision des Tnugdalus“ Albers von Lindberg: Literatur- und Frömmigkeitsgeschichte im ausgehenden 12. Jahrhundert (Mikrokosmos: Beiträge zur Literaturwissenschaft und Bedeutungsforschung, 54). Frankfurt am Main: Peter Lang.

50. Roth, F. W. E. (Ed.). (1884). Die Visionen der. hl. Elisabeth und die Schriften der Aebte Ekbert und Emecho von Schönau. Brünn: Verlag der „Studien aus dem Benedictiner- und CisterienserOrden".

51. Constable, G. (Ed.). (1980). The Vision of Gunthelm and Other Visiones Attributed to Peter the Venerable. Cluniac Studies, 6, 92-114.

52. Birkett, H. (Ed.). (2012). Visions of the Other World from the Cistercian Monastery of Melrose. Mediaeval Studies, 74, 101-141. 
53. Schmidt, P. G. (Ed.). (1988). Magnificus Cisterciensium ordo: Ordenkritik in einer Jenseitsvision. Mittellateinisches Jahrbuch, 23, 82-90.

54. Stevenson, J. (Ed.). (1847). Libellus de vita et miraculis s. Godrici, heremitae de Finchale auctore Reginaldo monacho Dunelmensi. London: J. B. Nichols and Son - Edinburgh: Laing and Forbes.

55. Acta Sanctorum Full-Text Database (2001). Vita Christinae virginis, cognomento Mirabilis auctore Thoma Cantipratano (AASS; Jul. V, 1727, pp. 650-660). Cambridge: Chadwyck-Healey.

56. Sauvage, E. P. M. (Ed.). (1883). Vitae B. Petri Abrincensis et B. Hamonis: Monachorum Coenobii Sviniacensis in Normannia. Analecta Bollandiana, 2, 479-500.

57.-58. Kompatscher Gufler, G. (Ed.). (2005). Herbert von Clairvaux und sein Liber miraculorum. Die Kurzversion eines anonymen bayerischen Redaktors: Untersuchung, Edition und Kommentar (Lateinische Sprache und Literatur des Mittelalters, 39). Bern: Peter Lang.

59. Stein, E. (Ed.). (1995). Leben und Visionen der Alpais von Cudot (1150-1211): Neuedition des lateinischen Textes mit begleitenden Untersuchungen zu Autor, Werk, Quellen und Nachwirkung, Tübingen: Gunter Narr Verlag.

60. Migne, J. P. (Ed.). (1855). Reineri monachi Lacrymarum libelli tres (PL, 204; col. 153-180). Paris: J. P. Migne.

61. Constable, G. (Ed.). (1956). The Vision of a Cistercian Novice. In G. Constable, \& J. Kritzeck (Eds.), Petrus Venerabilis 1156-1956: Studies and Texts Commemorating the Eighth Centenary of his Death (Studia Anselmiana, 40; pp. 95-98). Rome: Herder.

62. Assmann, E. (Ed.). (1979). Godeschalcus und Visio Godeschalci: Mit deutscher Übersetzung (Quellen und Forschungen zur Geschichte Schleswig-Holsteins, 74). Neumünster: K. Wachholtz.

63. Schmidt, P. G. (Ed.). (1985). Die Vision von Vaucelles (1195/1196). Mittellateinisches Jahrbuch, 20, 155-163.

64. Thurston, H. (Ed.). (1904). Visio monachi de Eynsham. Analecta Bollandiana, 22, 225-319.

65.-68. Easting, R., \& Sharpe, R. (Eds.). (2013). Peter of Cornwall's Book of Revelations. Oxford - Toronto: Pontifical Institute of Mediaeval Studies.

69. Schmidt, P. G. (Ed.). (1978). Visio Thurkilli: Relatore, ut videtur, Radulpho de Coggeshall. Leipzig: Teubner.

\section{Andere zitierte Visionen}

Visio cuiusdam viri religiosi. Ed. F. Böhner (1845). Zwei lateinische Gedichte aus dem Mittelalter. Zeitschrift für deutsches Alterthum, 5, 463-470.

Visio prioris de Cogeshala. Ed. R. Easting, \& R. Sharpe (2013). Peter of Cornwall's Book of Revelations (p. 294). Oxford - Toronto: Pontifical Institute of Mediaeval Studies.

Visio Stephani. Ed. J. P. Migne (1862). Sancti Gregorii papae Dialogorum libri IV. In Idem (Ed.), Gregorii papae I. opera omnia (Tom. III, PL, 77; col. 384A-384B). Paris: J. P. Migne.

Visio Sunniulfi. Ed. B. Krusch (1951). Gregorii episcopi Turenensis libri historiarum X (MGH, SSRM, I,1; p. 166). Hannoverae: Impensis Bibliopolii Hahniani.

Visio unius fratris Claravallensis. Ed. G. Kompatscher Gufler (2005). Herbert von Clairvaux und sein Liber miraculorum. Die Kurzversion eines anonymen bayerischen Redaktors: Untersuchung, Edition und Kommentar (Lateinische Sprache und Literatur des Mittelalters, 39; pp. 285-286). Bern - Berlin - Bruxelles - Frankfurt am Main - New York - Oxford - Wien: Peter Lang. 
Visio Wanningi. Acta Sanctorum Full-Text Database (2001). De S. Waningo confessore. Aliud fragmentum vitae (AASS, Jan. I, 1643, p. 592). Cambridge: Chadwyck-Healey.

Visio Wernheri. Ed. O. Abel, \& L. Weiland (1868). Casus monasterii Petrishusensis (MGH, SS, XX; pp. 664-665). Hannoverae: Impensis Bibliopolii Hahniani.

Visio Wolferadi. Ed. O. Abel, \& L. Weiland (1868). Casus monasterii Petrishusensis (MGH, SS, XX; p. 661). Hannoverae: Impensis Bibliopolii Hahniani.

\section{Andere Quellen}

Constable, G. (Ed.). (1956). The Vision of a Cistercian Novice. In G. Constable, \& J. Kritzeck (Eds.), Petrus Venerabilis 1156-1956: Studies and Texts Commemorating the Eighth Centenary of his Death (Studia Anselmiana, 40; pp. 95-98). Rome: Herder.

Emler, J. (Ed.). (1873). Život Vintíre poustevnika (FRB, I; pp. 337-346). Pragae: Nákladem Musea Království českého.

Jiroušková, L. (2006). Die Visio Pauli: Wege und Wandlungen einer orientalischen Apokryphe im lateinischen Mittelalter unter Einschluß der alttschechischen und deutschsprachigen Textzeugen (Mittellateinische Studien und Texte, 34). Leiden - Boston: Brill.

Kompatscher Gufler, G. (Ed.). (2005). Herbert von Clairvaux und sein Liber miraculorum. Die Kurzversion eines anonymen bayerischen Redaktors: Untersuchung, Edition und Kommentar (Lateinische Sprache und Literatur des Mittelalters, 39). Bern - Berlin - Bruxelles - Frankfurt am Main New York - Oxford - Wien: Peter Lang.

Migne, J. P. (Ed.). (1863). Helinandi Frigidi montis monachi Chronicon. In Idem (Ed.), Helinandi Frigidi montis monachi necnoc Guntheri Cisterciensis opera omnia (PL, 212, col. 771-1081). Paris: J. P. Migne.

Migne, J. P. (Ed.). (1862). Sancti Gregorii papae Dialogorum libri IV. In Idem (Ed.), Gregorii papae I. opera omnia (Tom. III, PL, 77; col. 149-430). Paris: J. P. Migne.

Migne, J. P. (Ed.). (1853). Venerabilis Guiberti Abbatis S. Mariae de Novigento opera omnia. In Idem (Ed.), De vita sua sive Monodiarum libri tres (PL, 156, col. 837-962). Paris: J. P. Migne.

Ribbeck, O. (Ed.). (1895). Vergilius: Aeneis. Leipzig: Teubner.

Schmidt, P. G. (Ed.). (1997). Visio Alberici: Die Jenseitswanderung des neunjährigen Alberich in der vom Visionär um 1127 in Monte Cassino revidierten Fassung. Stuttgart: Steiner.

\section{Sekundärliteratur}

Benz, M. (2013). Gesicht und Schrift. Die Erzählung von Jenseitsreisen in Antike und Mittelalter. Berlin - Boston: De Gruyter.

Carozzi, C. (1994). Le voyage de l'âme dans l'au-delà, d'après la littérature latine (Ve-XIII' siècle). Rome: École française de Rome.

Díaz y Díaz, M. C. (1985). Visiones del más allá en Galicia durante la Alta Edad Media. Santiago de Compostela: Biblioteca de Galicia.

Dinzelbacher, P. (1993). Nova visionaria et eschatologica. Mediaevistik, 6, 45-85.

Dinzelbacher, P. (1991). Revelationes (Typologie des sources du Moyen Âge occidental, 57). Turnhout: Brepols. 
Dinzelbacher, P. (1989). Mittelalterliche Visionsliteratur: Eine Anthologie. Darmstadt: Wissenschaftliche Buchgesellschaft Darmstadt.

Dinzelbacher, P. (1981). Vision und Visionsliteratur im Mittelalter (Monographien zur Geschichte des Mittelalters, 23). Stuttgart: Anton Hiersemann Stuttgart.

Dinzelbacher, P. (1979). Reflexionen irdischer Sozialstrukturen in mittelalterlichen Jenseitsschilderungen. Archiv für Kulturgeschichte, 61(1), 16-34.

Dus, J. A. (Ed.). (2007). Proroctvi a apokalypsy: Novozákonni apokryfy III. Praha: Kosmas.

Fros, H. (1988). Visionum medii aevi latini repertorium. In W. Verbeke, D. Verhelst, \& A. Welkenhuysen (Eds.), The Use and Abuse of Eschatology in the Middle Ages (pp. 481-498). Leuven: Leuven University Press.

Gaiffier de, B. (1945). La légende de S. Julien l'Hospitalier. Analecta Bollandiana, 63, 145-219.

Gardiner, E. (1993). Medieval Visions of Heaven and Hell: A Sourcebook (Garland Medieval Bibliographies, 11). New York - London: Garland Publishing.

Gebauer, Ch. (2013). Visionskompilationen: Eine bislang unbekannte Textsorte des Hoch- und Spätmittelalters (Arbeiten zur historischen und systematischen Theologie, 19). Berlin: Lit Verlag.

Le Goff, J. (1998). Středověká imaginace [L'Imaginaire médiéval]. Praha: Argo.

Schmidt, P. G. (Ed.). (1987). Die Vision des Bauern Thurkill: Visio Thurkilli mit deutscher Übersetzung. Leipzig: Teubner.

Weitbrecht, J. (2011). Aus der Welt. Reise und Heiligung in Legenden und Jenseitsreisen der Spätantike und des Mittelalters. Heidelberg: Winter.

Zaleski, C. (1993). Nah-Todeserlebnisse und Jenseitsvisionen vom Mittelalter bis zur Gegenwart. Frankfurt am Main - Leipzig: Insel-Verlag.

Mgr. Jan Slíva / jsliva@mail.muni.cz

Department of Classical Studies

Masaryk University, Faculty of Arts

Arna Nováka 1, 60200 Brno, Czech Republic 